\title{
Antibiotic use and knowledge in the community in Kalamoon, Syrian Arab Republic: a cross-sectional study
}

F. Barah and V. Gonçalves ${ }^{2}$

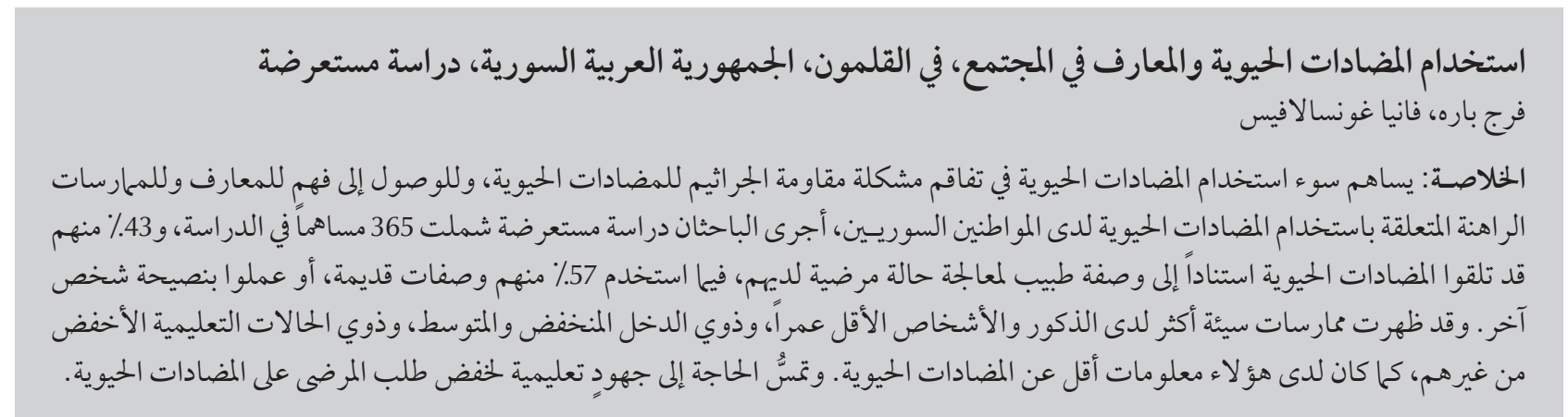

ABSTRACT Antibiotic misuse contributes to the growing problem of microbial resistance. To understand the current knowledge and practices regarding antibiotic use among Syrians, we conducted a cross-sectional study of 430 randomly selected adult residents of Kalamoon in the Syrian Arab Republic using a questionnaire. A high proportion (85\%) had taken antibiotics in the past 4 weeks and 34\% were not aware of the dangers of antibiotics. Of 365 participants, only $43 \%$ were prescribed the antibiotic by a physician to treat the condition, while $57 \%$ used an old prescription or took someone else's advice. Males, younger individuals, and those with low and medium income and lower educational status showed poorer practice and lower knowledge towards antibiotics. Educational efforts are needed to reduce patient demand for antibiotics.

Utilisation et connaissance des antibiotiques dans la population de Kalamoon (République arabe syrienne) : une étude transversale

RÉSUMÉ La mauvaise utilisation des antibiotiques joue un rôle dans le problème croissant de la résistance microbienne. Pour comprendre les connaissances et les pratiques actuelles en matière d'utilisation des antibiotiques au sein de la population syrienne, nous avons réalisé une étude transversale par questionnaire auprès de 430 adultes choisis au hasard parmi les habitants de Kalamoon, en République arabe syrienne. Une forte proportion d'entre eux (85\%) avait pris des antibiotiques au cours des quatre semaines qui précédaient l'étude et $34 \%$ n'étaient pas conscients du danger que présentent les antibiotiques. Sur 365 participants, seuls $43 \%$ s'étaient vus prescrire des antibiotiques par un médecin pour traiter leur maladie, alors que $57 \%$ avaient utilisé une ancienne ordonnance ou avaient demandé conseil à quelqu'un d'autre. Les plus mauvaises pratiques en matière d'utilisation des antibiotiques et les plus faibles connaissances sur le sujet ont été observées chez les hommes, les individus plus jeunes et ceux ayant des revenus faibles et moyens et un niveau d'éducation inférieur. Des actions éducatives sont nécessaires pour que les patients réduisent leur demande d'antibiotiques.

${ }^{7}$ Division of Microbiology, Department of Biochemistry and Microbiology; ${ }^{2}$ Department of Pharmaceutics, Faculty of Pharmacy, Private University of Kalamoon, Deratiah, Syrian Arab Republic (Correspondence to F. Barah: farajbarah@hotmail.com).

Received: 02/06/08; accepted: 16/07/08 


\section{Introduction}

Microbial resistance to many antimicrobial agents is a growing problem worldwide. There are various reasons for this problem; these include bacterial-related factors [1], and human-related factors. One of the most important humanrelated factors is the misuse of antibiotics (taking unnecessary doses when not needed or for an illnesses that does not require antibiotics, taking an overly large doses of antibiotics, or taking too low a dose of antibiotics) [2,3].

To target the misuse of antibiotics, most countries have laws that prevent selling these medications in pharmacies without a medical prescription. In the Syrian Arab Republic, the Ministry of Health passed a law (Number 2/T, dated $12 / 1 / 1988)$ that determined which drugs could be sold to individuals without a medical prescription and antibiotics were clearly excluded [4]. Another law (Number $2 / \mathrm{T}$, dated 23/1/1992) prevents pharmacists from reselling prescribed antibiotic to the same individual without the permission of a physician and also prevents physicians for prescribing an antibiotic more than twice to treat the same infection for the same individual [4]. However, unnecessary prescribing by physicians, random selling by pharmacists and patients' demands, linked with a lack of understating of antibiotic effectiveness, are common practice in the Syrian community.

To solve the problem of antibiotic misuse, a more thorough understanding of what influences the development and expression of patients' expectations is needed. Understanding patients' knowledge and practices may facilitate more effective communication between physicians, pharmacists and patients and help in the development of strategies to educate patients and the public [5]. Evidence suggests that educational interventions directed at patients, physicians and pharmacists can increase patients' knowledge and awareness, as well as reduce the frequency with which physicians prescribe antibiotics inappropriately and pharmacists sell antibiotics indiscriminately $[6-8]$.

This study was designed therefore to provide an insight of the current knowledge and practices regarding antibiotic use among individuals living in the Syrian Arab Republic. We also attempted to identify demographic characteristics associated with particular knowledge and practices and to determine whether an individual's knowledge of risks associated with taking antibiotics was associated with recent antibiotic use. Identifying subgroups of the population with high levels of antibiotic use and misconceptions about antibiotic consumption will help public health officials target and track the impact of interventions. Information obtained from this study will provide further understanding in the development and evaluation of health education and prevention strategies.

\section{Methods}

\section{Study design}

A preliminary cross-sectional study was carried out from 1 March to 30 April 2007 to evaluate the current knowledge and practices regarding the use of antibiotics in Kalamoon region in the Syrian Arab Republic. This region is representative of other regions in the country, due to their demographic similarities [9]. The present study received ethical approval from the Pharmacy College Council of the Private University of Kalamoon.

\section{Sample}

The study was carried out in 2 of 4 cities in Kalamoon region, Deratiah and Nabek which are near to the University of Kalamoon. Households (556) were randomly selected from a list of households in the main streets of the 2 cities. We visited as many households as possible within the study duration.
Home visits were conducted by trained research assistants who administered a questionnaire to participants about their antibiotic consumption. Only one member of the household, selected randomly, completed the questionnaire. Those under 18 years of age and those unable to understand Arabic were excluded from the study. Informed consent was obtained from all participants.

\section{Research instrument}

The questionnaire employed was adapted from a research carried out by Eng and colleagues [10] and modified for the present study. The questionnaire was translated into Arabic by the first author and back translated by one of the research assistants. It was pilot tested on a small sample of students and workers at the university and appropriate amendments made.

Participants were asked if they had taken antibiotics in the past 4 weeks, how they obtained the antibiotic (categorized as: antibiotic was prescribed by the physician; used an old prescription or took someone's advice) and how they used the antibiotic (categorized as: as prescribed by the physician/ pharmacist; stopped using it when felt better; continued the full dose even if felt better; changed the antibiotics if did not feel better immediately). Participants were also asked if they were aware of any health dangers associated with taking antibiotics. Respondent's knowledge of health dangers associated with taking antibiotics were categorized as: emerging drug resistance; allergies/reactions; adverse effect on normal flora; unhealthy to take drugs in general; misuse/overuse of antibiotics; need a physician's consultation before taking; other reasons; or don't know. Demographic characteristics of the participants, such as sex, age, income level and education level, were also recorded.

Completion of the questionnaire took approximately 10 minutes. Confidentiality regarding the participants' 


\begin{tabular}{|c|c|}
\hline \multicolumn{2}{|c|}{$\begin{array}{l}\text { Table } 1 \text { Demographic characteristics of } \\
\text { the participants }\end{array}$} \\
\hline Characteristic & $\begin{array}{l}\text { No. }(\%) \\
(n=430)\end{array}$ \\
\hline \multicolumn{2}{|l|}{ Age (years) } \\
\hline $18-24$ & $84(20)$ \\
\hline $25-39$ & $160(37)$ \\
\hline $40-59$ & $144(33)$ \\
\hline$\geq 60$ & $42(10)$ \\
\hline \multicolumn{2}{|l|}{ Sex } \\
\hline Male & $223(52)$ \\
\hline Female & $207(48)$ \\
\hline \multicolumn{2}{|l|}{ Area of residence } \\
\hline Deratiah & $214(50)$ \\
\hline Nabek & $216(50)$ \\
\hline \multicolumn{2}{|l|}{ Education $^{a}$} \\
\hline Below baccalaureate & $204(49)$ \\
\hline Baccalaureate $^{b}$ & $94(23)$ \\
\hline University student & $47(11)$ \\
\hline Higher education & $73(17)$ \\
\hline \multicolumn{2}{|l|}{ Income $e^{c, d}$} \\
\hline High & $52(15)$ \\
\hline Medium & $189(55)$ \\
\hline Low & $105(30)$ \\
\hline
\end{tabular}

anformation not available for 12 participants; ${ }^{b}$ high-school diploma; 'respondents were asked to rate their income level as high, medium or low ${ }^{d}$ information not available for 84 participants.

personal details and questionnaire's answers was assured.

\section{Statistical analysis}

Data was analysed using the SPSS, version 13.0.Descriptive statistics were used to describe the sample characteristics, use of antibiotics and awareness of antibiotics use. We assessed relationships between participants' demographic characteristics and their responses to the questions about antibiotics consumption using non-parametric statistical tests to compare categorical variables (chi-squared test). The level of significance was set at $P \leq 0.05$.

\section{Results}

A total of 445 individuals out of 556 approached agreed to participate in the study ( $80 \%$ response rate). Of these, 15 were excluded from the analysis because of incomplete data in the majority of the questionnaire. Thus the final sample as analysed consisted of 430 participants. Most of the participants were males (223, 52\%) and were aged 25-39 years $(160,37 \%)$. Table 1 presents the demographic characteristics of the participants.

Results showed that 366 (85\%) of the respondents had taken antibiotics in the 4 weeks prior to the study. There were no statistically significant differences in recent antibiotic use by sex or age. However, income $\left(\chi_{2}^{2}=14.06, \mathrm{Z}\right.$ $P=0.001)$ and education $\left(\chi_{3}^{2}=10.99\right.$, $P=0.012$ ) were significantly associated with recent antibiotic use. Participants within the medium income level and those with a baccalaureate (equivalent to high-school diploma) were more likely to have taken antibiotics (Table 2).
Out of 365 participants who indicated how they obtained the antibiotic, 157 (43\%) were prescribed by a physician to treat the condition, while 208 (57\%) used an old prescription or took someone else's advice. Age was significantly associated with the source of obtaining antibiotics $\left(\chi_{1}^{2}=8.63\right.$, $P=0.003)$. Following the advice of someone else other than the doctor or using an old prescription decreased with age. The highest use of antibiotics prescribed by someone other than the doctor was in the 18-24-year age category (63\%) (Table 2).

Participants were asked how they used the antibiotic and of the 425 participants who responded to this question, only 30\% reported that they took the antibiotic exactly as the physician prescribed (Table 3).

The results showed 145 (34\%) respondents were not aware or were unsure of the health dangers associated

\begin{tabular}{|c|c|c|c|c|}
\hline Characteristic & $\begin{array}{l}\text { Took antibiotics } \\
\text { in the past } 4 \\
\text { weeks (\%) }\end{array}$ & $\begin{array}{l}\text { Statistical } \\
\text { data }\end{array}$ & $\begin{array}{l}\text { Took antibiotics on } \\
\text { advice of someone other } \\
\text { than a doctor or used old } \\
\text { prescription (\%) }\end{array}$ & $\begin{array}{l}\text { Statistical } \\
\text { data }^{\mathrm{a}}\end{array}$ \\
\hline Sex & & $P=1.0^{\mathrm{b}}$ & & $P=0.245^{b}$ \\
\hline Male & 85 & & 60 & \\
\hline Female & 85 & & 54 & \\
\hline Age (years) & & $\chi_{3}^{2}=6.48$ & & $\chi_{3}^{2}=8.63$ \\
\hline $18-24$ & 87 & $P=0.09$ & 63 & $P=0.003$ \\
\hline $25-39$ & 89 & & 61 & \\
\hline $40-59$ & 83 & & 58 & \\
\hline$\geq 60$ & 74 & & 23 & \\
\hline Income & & $\chi_{2}^{2}=14.06$ & & $\chi_{2}^{2}=2.072$ \\
\hline High & 83 & $P=0.001$ & 69 & $P=0.355$ \\
\hline Medium & 89 & & 57 & \\
\hline Low & 72 & & 62 & \\
\hline Education & & $\chi_{3}^{2}=10.99$ & & $\chi_{3}^{2}=2.55$ \\
\hline Baccalaureate & 80 & $P=0.012$ & 54 & $P=0.314$ \\
\hline Baccalaureate & 93 & & 66 & \\
\hline $\begin{array}{l}\text { University } \\
\text { student }\end{array}$ & 89 & & 55 & \\
\hline $\begin{array}{l}\text { Higher } \\
\text { education }\end{array}$ & 90 & & 57 & \\
\hline
\end{tabular}

${ }^{a} \chi^{2}$ for linear trend.

${ }^{b}$ Fisher exact test. 


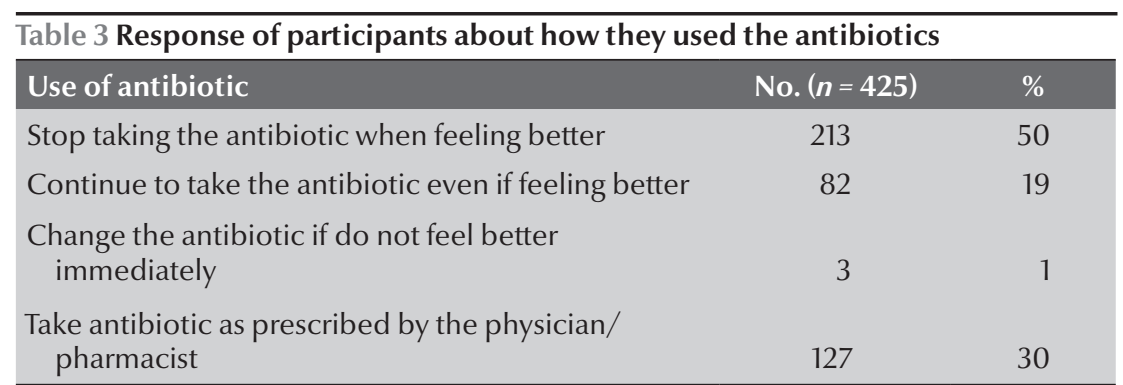

Information was not available for 5 participants.

\begin{tabular}{lcc}
\hline $\begin{array}{l}\text { Table } 4 \text { Awareness of the dangers of antibiotics by sociodemographic } \\
\text { characteristic }\end{array}$ & $\begin{array}{c}\text { Not aware of the health } \\
\text { dangers of antibiotics } \\
\text { use (\%) }\end{array}$ & Statistical data $^{a}$ \\
\hline $\begin{array}{l}\text { Characteristic } \\
\text { Sex }\end{array}$ & $\chi_{1}^{2}=4.00, P=0.045$ \\
Male & 38 & \\
Female & 29 & \\
Age (years) & & \\
18-24 & 33 & \\
$25-39$ & 29 & \\
$40-59$ & 35 & \\
$\geq 60$ & 48 & \\
Income & & \\
High & 23 & \\
Medium & 30 & \\
Low & 45 & \\
Education & & \\
Baccalaureate & 40 & \\
Baccalaureate & 29 & \\
University student & 21 & \\
Higher education & & \\
\hline
\end{tabular}

${ }^{a} \chi^{2}$ for linear trend.

\begin{tabular}{lcc}
\hline $\begin{array}{l}\text { Table } 5 \text { Response of participants about the dangers associated with antibiotics } \\
\text { use }\end{array}$ & No. $(\boldsymbol{n}=\mathbf{4 2 7})$ & $\%$ \\
Danger mentioned & 44 & 10 \\
Emergence of drug resistance & 55 & 13 \\
Allergies/adverse reactions & 11 & 3 \\
Antibiotics kill normal flora & 31 & 7 \\
Generally unhealthy to take antibiotics & 10 & 2 \\
Overdose of antibiotics & 1 & 0.2 \\
Antibiotics should not be used without the physician & 66 & 15 \\
$\quad$ prescription & 64 & 15 \\
Various & & \\
Know there are dangers but don't know what they are &
\end{tabular}

Information was not available for 3 participants.

Participants could give more and one danger. with taking antibiotics. Income $\left(\chi_{1}^{2}=\right.$ 8.92, $P=0.003)$, $\operatorname{sex}\left(\chi_{1}^{2}=4.00, P=0.045\right)$ and education $\left(\chi_{3}^{2}=8.88, P=0.031\right)$ were significantly associated with lack of awareness of the dangers of antibiotics. Those not aware of dangers associated with antibiotic use were significantly more likely to be males and have less than a baccalaureate (high-school diploma). Lack of awareness increased with the decrease in income (the highest percentage of those not aware of the dangers was $45 \%$ in the low-income category) (Table 4). There was no association between use of antibiotics in the past 4 weeks and awareness of the health dangers associated with taking antibiotics. Of those aware of the health dangers, only $10 \%$ mentioned factors related to the emergence of drug resistance as a consequence of antibiotic use (Table 5).

\section{Discussion}

This study is the first to assess the current knowledge and practices in the consumption of antibiotics in the Syrian Arab Republic. Surprisingly high rates of antibiotic use were found. In fact, $85 \%$ of adult respondents (> 18 years old) reported having used antibiotics in the past 4 weeks. In addition, the majority of individuals (57\%) had followed the advice of someone other than the physician or had used an old prescription before taking the antibiotic; only $43 \%$ stated that the antibiotic was prescribed by the physician to treat the condition. These findings clearly indicate how much the laws that control the sale of antibiotics in pharmacies in the Syrian Arab Republic are ignored.

Overall, 50\% of the respondents in this cross-sectional study reported that they stopped taking the antibiotic once they felt better. This misconception in the use of antibiotics may put the consumer at unnecessary risk for infection or relapse with resistant bacterial strains. Only 19\% of the participants 
reported that they took the antibiotic as prescribed by the physician. Given the high rates of antibiotic use, it is interesting that $66 \%$ of the participants said they were aware of the dangers associated with antibiotic use while $34 \%$ were not. However, as our analysis confirmed, there was no association between use of antibiotics in the last 4 weeks and awareness of the health dangers of antibiotics. Among those aware of the dangers, only $10 \%$ mentioned the emergence of drug resistance as a consequence of antibiotic use, while $15 \%$ said that they knew there were dangers in taking antibiotics but they did not know what they were. These results demonstrate an evident lack of knowledge and poor practice towards antibiotic consumption.

This study identified individuals in demographic groups who had both higher levels of poor practice and lower levels of knowledge about the potential adverse impact of antibiotics. These groups included individuals with low and medium income, lower educational status (generally with high-school certificate or below), males and those in younger age groups (18-24 years old). Efforts should be focused to reach these groups in any health education programme to change patient expectations and to reduce the pressure on providers (physicians and pharmacists) to prescribe antibiotics inappropriately.

Our findings also indicate the need for further information on antibiotic use. First, population-based studies are needed not only to measure antibiotic use but also to determine the reasons that people use them. Such studies should explore the attitudes, motivations and expectations that lead people to use or not use antibiotics. Second, future studies should include more clearly defined measures of patients' knowledge. Better measures of knowledge may involve asking respondents to differentiate between antibiotics and other types of prescription medicine and to identify types of infections requiring antibiotics.

Our study has some limitations. We used a cross-sectional design so it was not possible to examine changes in knowledge and practice towards antibiotics over time [10]. Furthermore, despite of our effort to design a simple questionnaire, it remains unclear how well the participants in this study understood illness and treatment explanations, which inevitably require some use of medical terminology [11]. In fact, several studies have reported that patients frequently do not have accurate knowledge about antibiotics [12]. As Hong and colleagues showed, patients often could not identify if a medication was an antibiotic and that several patients considered "antibiotics" to be any prescribed medication [13]. The quality of experience of the health care system was not examined in this study. Details about the communication with physicians and pharmacists regarding antibiotic needs were not assessed.

Our study highlights several important concerns related with the use of antibiotics in Syrian Arab Republic that require attention. There is a high rate of antibiotic consumption, which leads to the question of how appropriate and necessary their use is by the community. In fact, there was a lack of understanding of proper use of antibiotics within the studied communities and a lack of awareness of the dangers of antibiotic use. Educational efforts on a national basis should be employed, such as public information campaigns, improved communication about antibiotic appropriateness between health professionals and patients, together with strict implementation of the laws. These are vital if patient demand for antibiotics is to be reduced and public health and economic consequences are to be avoided.

\section{Acknowledgements}

We would like thanks the 5th-year students in the Pharmacy College, Kalamoon University (Raya Zin Al-Din, Roba Halak, Rim Al-Hafeth, Zin Kahil, Lama Hamami, Layla Okati, Dalia Hakim, Jamil Batah, Wael Krish, Mazen Doraki, and Zakaria Sokar) who collected the data, and the statistician Mr Ayman Mohammad for his valuable help.

\section{References}

1. Harvey RA, Champe PC, Fisher BD. Lippincott's illustrated reviews in microbiology, 2nd ed. Philadelphia, Lippincoot Williams \& Wilkins, 2007.

2. Bauchner H, Pelton SI, Klein JO. Parents, physicians, and antibiotic use. Pediatrics, 1999, 103:395-401.

3. Cockburn J, Pit S. Prescribing behaviour in clinical practice: patients' expectations and doctors' perceptions of patients' expectations: A questionnaire study. British medical journal, 1997, 315:520-3.

4. Syrian Syndicate for Pharmacists. [Laws and orders that coordinate pharmacy career in Syria]. Damascus, Syrian Syndicate for Pharmacists, 1994 [In Arabic].
5. Kravitz RL et al. Prevalence and sources of patients' unmet expectations for care. Annals of internal medicine, 1996, 125:730-7.

6. Belongia EA et al. A community intervention trial to promote judicious antibiotic use and reduce penicillin-resistant Streptococcus pneumoniae carriage in children. Pediatrics, 2001, 108:575-83.

7. Finkelstein JA et al. Reducing antibiotic use in children: a randomized trial in 12 practices. Pediatrics, 2001, 108:1-7.

8. Trepka MJ et al. The effect of a community intervention trial on parental knowledge and awareness of antibiotic resistance and appropriate antibiotic use in children. Pediatrics, 2001, 107:E6. 
9. [Annual Report of the Syrian Central Bureau of Statistics. 1998. Damascus, Syrian Central Bureau of Statistics, 1998 [In Arabic].

10. Eng JV et al. Consumer attitudes and use of antibiotics. Emerging infectious diseases, 2003, 9:1128-35.

11. Palmer DA, Bauchner H. Parents' and physicians' views on antibiotics. Pediatrics, 1997, 99:E6.
12. Chretien JH et al. Abuse of antibiotics. A study of patients attending a university clinic. Archives of internal medicine, 1975, 135:1063-5.

13. Hong JS, Philbrick JT, Schorling JB. Treatment of upper respiratory infections: Do patients really want antibiotics? American journal of medicine, 1999, 107:511-5.

\section{Public health campaign: getting the message across}

Public health campaign: getting the message across takes a historical look at the power of posters to persuade people to change their behaviour. It charts decades of changing health priorities, advertising trends and government regulations, inviting the reader to reflect on how public health campaigns have evolved, and how they could be improved. The book contains a large global sample of public health posters with translations in Arabic, Chinese, English, French, Spanish and Russian.

It is designed to provide public health professionals, policy-makers, programme managers and students of public health with an important resource; one that will be equally useful to anyone with an interest in graphics, social mobilization or health. The eight chapters contain a selection of posters from all WHO regions, introduced with a brief history.

Further information about this and other WHO publications can be found at: http:/ www.who.int/publications/en/ 